Article

\title{
Governing the Humanitarian Knowledge Commons
}

\author{
Femke Mulder \\ Department of Organization Sciences, Vrije Universiteit Amsterdam, 1081 HV Amsterdam, The Netherlands; \\ E-Mail: f.mulder@vu.nl
}

Submitted: 14 April 2020 | Accepted: 16 July 2020 | Published: 10 December 2020

\begin{abstract}
Humanitarians and bureaucrats who are mandated to work together in complex emergencies face many challenges, especially in settings marked by conflict and displacement. High on the list of challenges are barriers to sharing knowledge freely. These barriers include (self)censorship, contested framings and priorities, deliberate ICT black-outs, and the withholding (or not collecting) of mission-critical information. These barriers exacerbate the gaps in knowledge sharing that occur as a result of a lack of time or capacity. This article conceptualises crisis knowledge as a 'commons': a shared resource that is subject to social dilemmas. The enclosure of the knowledge commons-brought about by the barriers outlined abovehampers daily operations as well as efforts to improve the situation in the long term. Trust is key to effective commons governance, as actors need to sacrifice personal benefits (e.g., control over information) for a collective good (e.g., shared learning). Knowledge and trust are deeply interlinked, as shared ways of knowing (alignment) foster trust, and trust fosters the sharing of knowledge. Given the hierarchical nature of humanitarian relationships, this article explores how power and networks shape this dynamic. It focuses on the humanitarian response to the 2018 Guji-Gedeo displacement crisis in the south of Ethiopia. It presents a qualitative analysis of how the governance arrangements that marked this response shaped emergency operations centres' ability to manage the local knowledge commons effectively. It shows how in Guji-Gedeo, these arrangements resulted in a clustering of trust that strengthened barriers to knowledge sharing, resulting in a partial enclosure of the knowledge commons.
\end{abstract}

\section{Keywords}

bureaucrats; commons governance; complex emergency; emergency operations centre; Ethiopia; ethnic conflict; humanitarians; knowledge commons; trust; wicked problem

Issue

This article is part of the issue "The Politics of Disaster Governance" edited by Dorothea Hilhorst (Erasmus University Rotterdam, The Netherlands), Kees Boersma (Vrije Universiteit Amsterdam, The Netherlands) and Emmanuel Raju (University of Copenhagen, Denmark).

(C) 2020 by the author; licensee Cogitatio (Lisbon, Portugal). This article is licensed under a Creative Commons Attribution 4.0 International License (CC BY).

\section{Wicked Problems: Problems of Alignment in Knowledge and Trust}

This article addresses one of the main challenges humanitarians and bureaucrats face in their efforts to respond to complex emergencies: barriers to the free and open sharing of knowledge. This article is premised on the idea that all stakeholders have knowledge that is relevant to the crisis at hand, but that only a part of this knowledge gets incorporated into humanitarian communications and information products. The article's purpose is to analyse how the relationships of power that underpin a humanitarian intervention influence the decisions and actions of stakeholders to withhold, exclude, block, or reframe knowledge prior to sharing. Its focus is on the humanitarian governance arrangements that guide collaboration between humanitarians and bureaucrats in the field. It explores how international collaborative mechanisms relate to state actors (see also Hendriks \& Boersma, 2019) given the intra-state power struggles that mark conflict settings (Melis \& Hilhorst, in press). It aims to understand how these power relationships shape what knowledge gets included, what gets excluded, and what gets reframed: In other words, how multiple knowledges are filtered and translated into shared information. This issue has direct practical relevance 
because barriers against the free and open sharing of knowledge limit how effectively a complex emergency can be addressed. Indeed, these barriers not only undermine day to day operations on the ground by depriving actors of mission-critical information but also hamper learning about the causes that triggered the complex emergency in the first place. As such, this article will conclude with a practical recommendation as to how governance arrangements could be revised to foster a more free and open sharing of knowledge.

To explore the issues outlined above, this article presents a qualitative case study of the response to the 2018 Guji-Gedeo displacement crisis. This was a complex emergency in the south of Ethiopia in which 800,000 people became internally displaced. Complex emergencies are major humanitarian crises that are triggered by multiple interlinked problems, such as political instability, violence, climate change, social inequality, and poverty (Food and Agriculture Organization of the United Nations [FAO], n.d.). As a consequence, efforts to address them cut across jurisdictions, organisational mandates, authority structures, and group interests. This complexity, in terms of both root causes and institutional arrangements, makes complex emergencies wicked governance problems (e.g., Weber \& Khademian, 2008). Wicked governance challenges are characterised by a fragmented knowledge base and a lack of consensus as to how the underlying problems should be defined and, hence, solved (Daviter, 2019). Complex emergencies involve a wide range of actors, such as UN bodies, local bureaucrats and NGOs. Given their different (professional and geographic) backgrounds, these actors draw on different bases of prior knowledge in their efforts to make sense of humanitarian crises. In their endeavour to understand the multiple interlinked problems, they work through different logics, use different lenses, and set different priorities (Hilhorst, Desportes, \& de Milliano, 2019). The main challenge this poses to the governance of wicked problems springs from the interconnection between knowledge and trust (Henry \& Dietz, 2011). Actors who know in the same way, see in the same way, and are more likely to trust each other's intentions. By contrast, actors who diverge in both what they know and how they see things are likely to interpret the same event in different ways, ascribing dishonest intent to the other's framing (Henry \& Dietz, 2011). The interconnection between knowledge and trust is, to a significant extent, shaped by perceptions of shared identity and interests. A failure to link up a fragmented knowledge base can trigger a downwards spiral towards depleted trust. In a worstcase scenario, ways of knowing become entrenched in 'us versus them' thinking, resulting in a breakdown in collaboration.

Following Hess and Ostrom (2007), this article approaches knowledge as a 'commons': a resource shared by a group of people that is subject to social dilemmas (e.g., Henry \& Dietz, 2011). A social dilemma refers to a situation in which an actor benefits from act- ing in their own (or their group's) immediate self-interest unless the majority of actors involved choose to do so, in which case everybody loses. The main social dilemma that marks a knowledge commons is the question of whether to sacrifice the strategic (or financial) benefits of control over information for the shared benefits of a consolidated knowledge base. In the context of a knowledge commons, acting in one's immediate self-interest generally entails withholding, blocking, or reframing knowledge, i.e., enclosing a part of the commons. A large body of research has emerged (e.g., Ostrom, Gardner, \& Walker, 1994) on the incentives that shape commons members' behaviour. Trust is a central theoretical variable in this research: Actors are unlikely to sacrifice their own immediate benefits for the good of the collective if they do not believe that the latter will come through for them. Most studies focus on small, simple commons, where it is possible to explain actors' choices based on their direct interactions with others (e.g., Henry \& Dietz, 2011). However, the knowledge commons that pertains to complex emergencies is significantly more intricate. It is comprised of a wide range of actors at field, national, and global level. Members of such a commons never interact directly with the vast majority of other members. They cannot assess key attributes (such as trustworthiness) of these members based on direct interaction. For this reason, there is a growing recognition of the value of conceptualising complex commons as social networks (Henry \& Dietz, 2011) This lens draws attention to the ways in which relationships and affiliations influence what attributes (e.g., trustworthiness) commons members subconsciously ascribe to each other. It also highlights how these ties shape performative behaviour to signal an actor's position in a knowledge network to others. As the case study shows, networked power relationships can incentivise (self)censorship towards certain framings and narratives. Desportes, Mandefro, and Hilhorst (2019) highlight the resulting split between on the record and off the record humanitarian communications in Ethiopia. As per these examples, a network lens moves away from the rational actor model. It allows for an analysis of behaviour that is shaped by relationships and affiliations (such as subconscious associations and performative behaviour) as opposed to pure rational contemplation. This article follows this approach and understands the term commons as a social network.

When it comes to governing wicked problems, such as complex emergencies, commons scholars increasingly look to localised and network-based approaches (e.g., Ostrom, 2010). These approaches are seen as more effective than centralised, top-down 'command and control' approaches (e.g., Boersma, Ferguson, Groenewegen, \& Wolbers, 2014). One important reason for this is that they allow for robust action in the face of wicked problems (Ferraro, Etzion, \& Gehman, 2015). Robust action entails not defining and solving 'the problem' from above but instead fostering a plurality of local context-specific problem definitions and solutions towards a richer over- 
all knowledge commons. Figure 1 depicts a robust action approach to governing a knowledge commons in an ideal scenario. At its core, this approach aims to interconnect different knowledge clusters. The goal is not to impose one framing at the expense of others or to bring about one unified vision. Instead, the goal is to foster trust and a broad sense of common purpose by interlinking ways of knowing. This, in turn, facilitates local collaborationand hence resilience-in the face of complex emergencies (Aldrich, 2012).

From a social network perspective, the rationale for using a robust action approach to humanitarian knowledge governance is as follows: ways of knowing a governance issue can be conceptualised as fluid networks comprised of human and non-human actants, such as 'local bureaucrats' and 'humanitarian standards.' As outlined above, ways of knowing are deeply interlinked with a sense of shared identity and shared interests (e.g., Feldman, Khademian, Ingram, \& Schneider, 2006). As such, by rearranging the connections between actants (e.g., linking humanitarian standards to the knowledge and interests of local bureaucrats), commons' members become more closely aligned (Feldman et al., 2006). In this example, this would entail collectively linking the standards to participants' interests and professional identities through situation- and context-specific discussions, rather than imparting information about the standards in a top-down manner. This approach holds the potential to foster goodwill, understanding, and trust, which are key to collaboration (Aldrich, 2012). However, interlinking ways of knowing requires a participatory setup and the safeguarding of different perspectives and priorities (i.e., multivocality). If these preconditions are not met, actors are likely to question the legitimacy of the governance arrangements (e.g., Ansell \& Gash, 2008) and seek ways of 'working around' this set.

There are various tensions inherent in different forms of commons (network) governance, and management plays a core role in addressing these tensions (Provan \& Kenis, 2008). In humanitarian settings, fostering collaboration and trust between global/national actors and subnational authorities, local service providers, and local affected communities constitutes one of the main challenges. When it comes to complex commons such as these, facilitative leadership is key to redressing power imbalances and fostering multivocal participation towards greater trust and collaboration (e.g., Ansell \& Gash, 2008). This paper zooms in on the level of field emergency operations centres (EOCs) and the response coordinators' efforts to bring people to consensus and foster knowledge sharing on the ground. Its focus lies hereby on the power dynamics that underpin the humanitarian knowledge commons (networks). A central feature of the humanitarian sector is its deeply hierarchical nature (Barnett, 2011). Hence, the governance of a humanitarian knowledge commons tends to be centralised and marked by power asymmetries. In the context of a major response, it is normally brokered by external network governance bodies (NGBs), generally the national government and the United Nations Office for the Coordination of Humanitarian Affairs (UNOCHA). This article explores how the governance arrangements that marked the humanitarian response in Guji-Gedeo influenced the ability of response coordinators at the EOC to act as facilitative leaders. Focusing on knowledgetrust, this article addresses the research question: How do governance arrangements shape incentives towards enclosure of the knowledge commons?

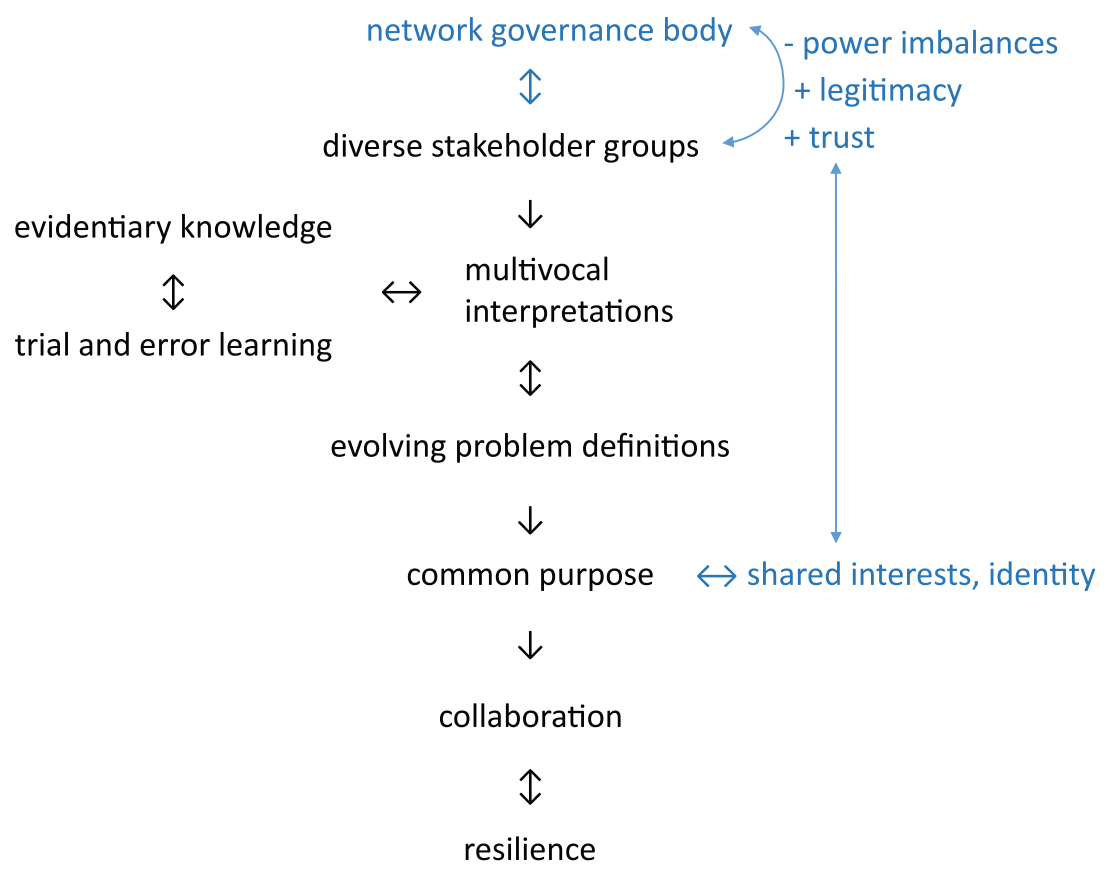

Figure 1. Robust action-knowledge governance for wicked problems (ideal scenario). Source: Author. 


\section{A Network-Power Lens}

This article aims to understand how the relationships of power that marked humanitarian governance arrangements in Guji-Gedeo shaped the knowledge commons at field level. It looks at how these power relationships influenced trust between stakeholder groups, as well as how it shaped their perceptions of the internal legitimacy of the governance set-up. Its focus is on how connections, affiliations, and network positions interlinked with different forms of power to shape stakeholders' incentives to act in their immediate self-interest versus in the interest of the collective response. This article takes a qualitative social network approach. This approach is great for exploring 'how' questions (Pratt, 2009), as it allows for a detailed exploration of network processes and motivations, taking into account the social dimensions of ties and networks and the relevance of context (Jack, 2008).

Different scholars have taken different approaches to power in management (see, for example, Fleming \& Spicer, 2014, for an overview). Gaventa encompasses much of this scholarship in his 'power cube' (2005), which is a three-dimensional tool for exploring how different levels, forms and spaces of power interlink in a specific context. This article builds on this work by exploring these interlinkages through a relational lens. Gaventa distinguishes between visible power (e.g., the power to coerce); hidden power (e.g., the power to manipulate); and invisible power (e.g., the power to shape people's beliefs and behaviour, such as through tropes, formal definitions, imagery, architecture, and so on). Gaventa refers to visible, hidden, and invisible power as different 'forms' of power. This article looks at both domination and the counter-power to subvert domination (Castells, 2007). These different forms of power play out at different levels. In a humanitarian setting, the 'global' level is the international community; the 'national' level refers to actors working at the national level, generally from the capital city; and the 'local' level refers to all activ- ity that takes place at the sub-national level. Gaventa also looks at different opportunities or 'spaces' for interaction. Given this article's focus, it looks instead at different realms of knowledge governance. These realms were identified during data analysis as second order themes (see Figure 3 under Section 3). Briefly, the moral realm governs what knowledge is right and important; the hierarchical realm governs which 'ranks' knowledge is included; the bureaucratic realm governs what knowledge is authorised; and the physical realm covers what knowledge can physically be shared and when (e.g., communications black-outs). On the basis of this analysis, Gaventa's power cube has been adjusted (see Figure 2). This adjusted power cube has been used for the analysis presented in this article.

\section{Methods}

The case study and findings presented in this article are based on three months of fieldwork in Ethiopia, carried out between September and December of 2018. During this period, the author was granted permission to attend coordination meetings at the Emergency Operations Centre in Dilla town, Gedeo. In addition, 33 semi-structured interviews were conducted with key stakeholders in Dilla town and at UN and NGO headquarters in Addis Ababa. Participants were selected based on their role, organisational affiliation, and location. The qualitative power-network approach outlined above informed the design of the interview protocol and the data analysis. For the analysis, all 33 interviews were fully transcribed, along with four coordination meetings at the EOC. These transcripts were analysed thematically and compared and contrasted with each other, with field notes, and with other primary sources (i.e., EOC minutes, photographs, posters, briefings, reports) and secondary sources (i.e., news articles, academic articles, and UN reports). The analysis constituted a relatively open process whereby the author went back and forth between

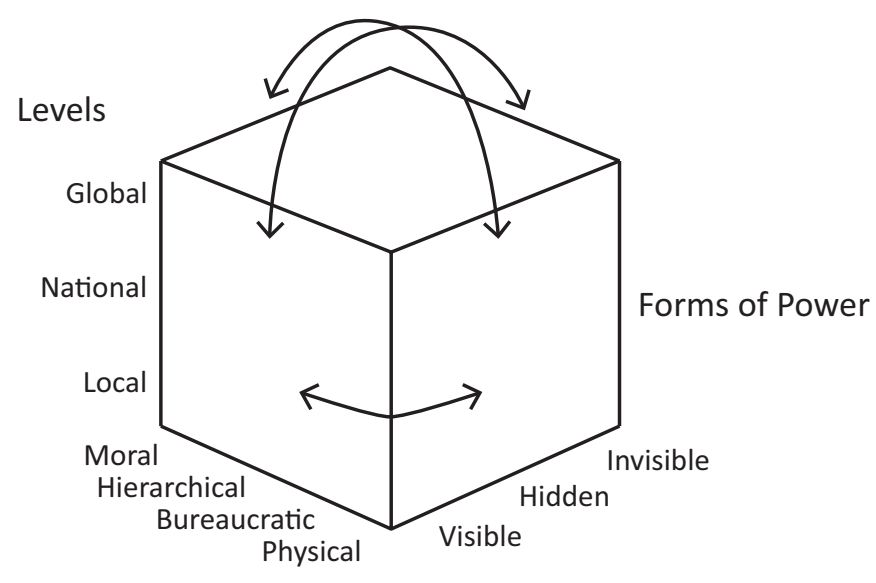

Realms of Knowledge Governance

Figure 2. The power cube, adapted for a power analysis of knowledge governance. Source: Author, adapted from Gaventa (2005). 
the theoretical framework and the data. In doing so, the author was able to refine her theoretical observations and create theoretical categories (Gioia, Corley, \& Hamilton, 2013). The data structure has been outlined in Figure 3: The 1st order concepts summarise statements made by informants and/or found in other primary and secondary sources. They are organised by 2 nd order themes, which centre on theory. These 2 nd order

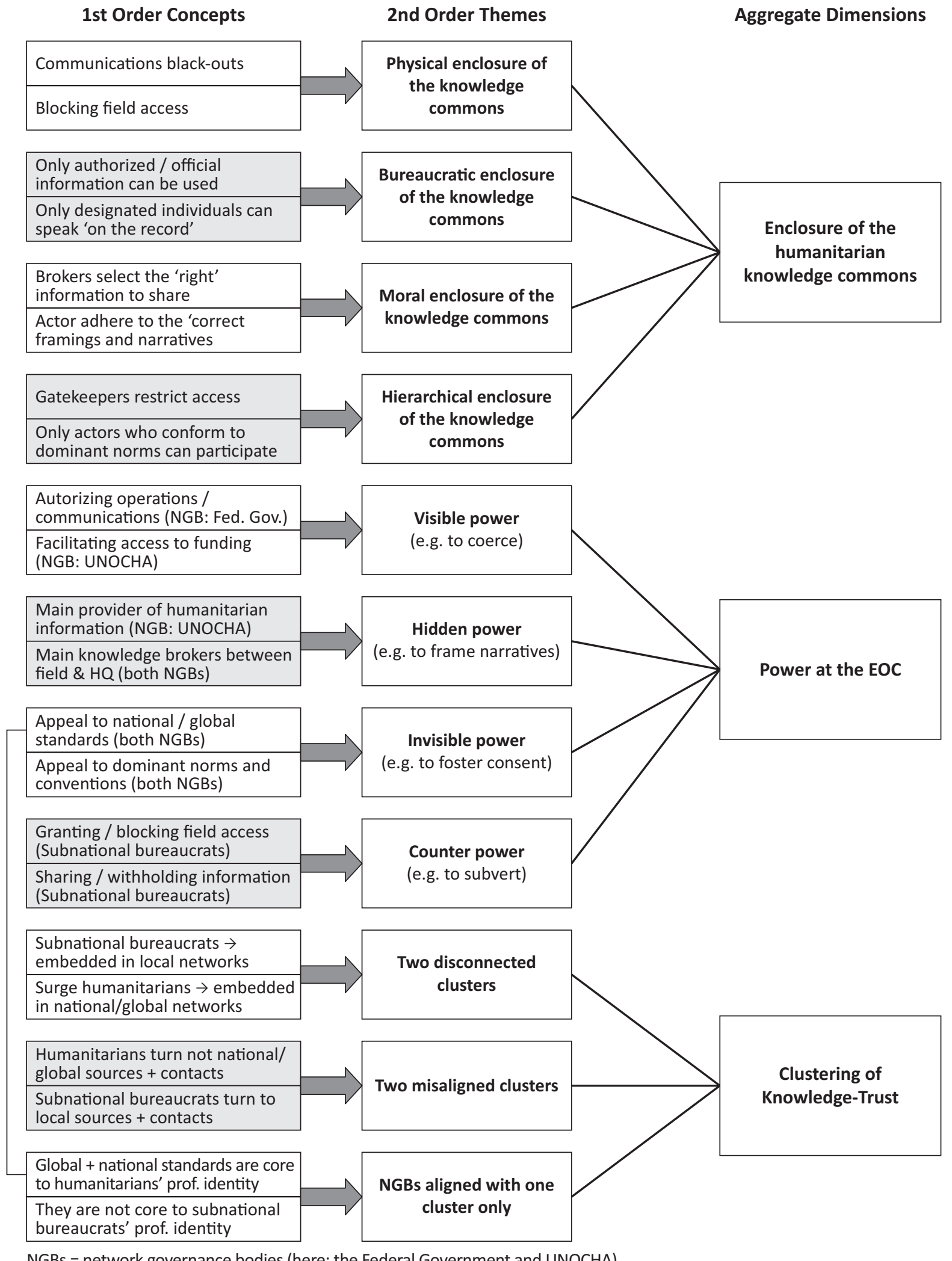

NGBs = network governance bodies (here: the Federal Government and UNOCHA)

Figure 3. Data structure. Source: Author. 
themes have, in turn, been combined into three aggregate dimensions.

The analysis this article provides is based on the theorised interplay between these themes and dimensions (this interplay is depicted in Figure 9 under Section 6).

\section{Background to the 2018 Guji-Gedeo Displacement Crisis}

As with all complex emergencies, it is contested why the Guji-Gedeo displacement crisis unfolded. This section provides some history and context from the literature to help the reader place the events. In line with this article's purpose, this is not intended as the definitive explanation as to 'what really caused the Guji-Gedeo displacement crisis.' The case study below focuses on events in 2018. That year, the country was still dealing with the aftermath of a severe and prolonged drought, brought on by El Nino. It hosted close to a million refugees from neighbouring countries. Furthermore, in addition to the Guji-Gedeo displacement crisis in the south, that year Ethiopia also faced major internal displacement crises in the east and the west of the country. As such, the attention and resources of the federal government and humanitarian community in Ethiopia were stretched.

The trigger that sparked the initial wave of displacement in Guji-Gedeo in 2018 was an outbreak of intercommunal violence. Ethiopia is home to multiple ethnic groups. After failed attempts at nationbuilding through assimilation and centralisation, in the early 1990s Ethiopia was restructured into an ethnofederation (Kefale, 2013). This means that the country was divided up into administrative regions along ethnolinguistic lines. Ethnicity, rather than nationality, became the vehicle for citizenship rights and entitlements. It also became the medium through which conflicts (e.g., over resources, over territory) came to be framed and understood (Kefale, 2013). The Gedeos and Gujis used to be neighbouring peoples living in the same province. They managed conflict and cooperation through traditional indigenous governance systems (Bekele, 2019; Debelo \& Jirata, 2018). However, in the early 1990s, an intrafederal boundary was drawn between them. The Gujis belong to the Oromo ethnic group and became part of the Oromia region, whereas the Gedeos were included in the SNNP region (Southern Nations, Nationalities and Peoples; see Figure 4). Like everywhere else in the country, this division was not tidy. Some argue that the resulting tensions are the reason why violent conflict broke out between the two groups (e.g., Debelo, 2012; Kefale, 2013).

Under ethnic federalism, Ethiopia's constitution promised wide-ranging powers to Ethiopia's regions. However, in practice, the federal government dominated

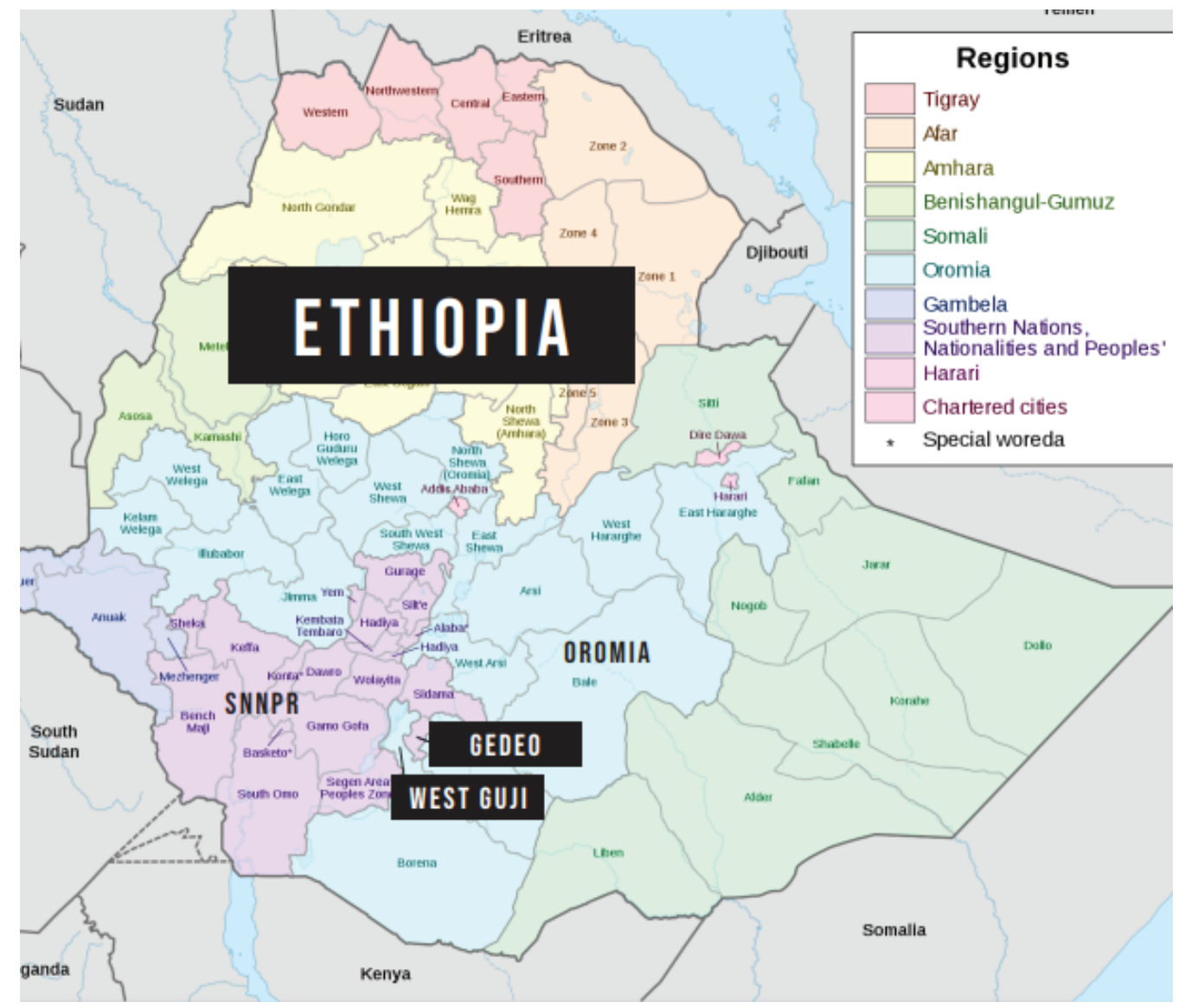

Figure 4. Map of the zones of Ethiopia, highlighting West Guji and Gedeo zones. Source: Yarnell (2018). 
this relationship and frequently intervened in the day-today activities of the regions (Kefale, 2013). The resulting power struggle shaped the humanitarian response that is the focus of this article.

\section{Case Study: The Humanitarian Response to the $\mathbf{2 0 1 8}$ Guji-Gedeo Displacement Crisis}

\subsection{The Main Challenge: Onboarding Subnational Bureaucrats in a Federal-Global Response}

In April 2018, a new prime minister came to power, Dr. Abiy Ahmed. He instituted a range of progressive reforms, including the easing state political controls. This may inadvertently have contributed to a flare up of ethnic tensions. That month, after two decades of relative peace, violent conflict broke out again between the Gedeos and the Gujis. This resulted in the internal displacement of 300,000 people. In response, subnational authorities launched an investigation and local traditional leaders undertook reconciliation efforts. They quickly declared the crisis over and encouraged the internally displaced people (IDPs) to return home. Nevertheless, two months later, in June 2018, the conflict flared up again, resulting in the internal displacement of 800,000 people. At this point, the federal government and humanitarian community decided to intervene. However, some subnational bureaucrats were wary of external interference:

$[T]$ he authorities even were not very keen on allowing...they would make it very difficult for you to get down to Dilla [town in Gedeo]. I mean, [they would say] there's no purpose of you going there. We are on top of issues. Most of the IDPs have already returned. So, what's the point of you going there? So that was the kind of attitude. (UN staff, November 3, 2018)

Experienced UN and federal coordinators negotiated access and rolled out two EOCs, one in Gedeo (Dilla town) and one in West Guji (Bule Hora town). At this point, humanitarian agencies came down to set up field offices. The purpose of the EOCs was to connect and coordinate between the local, national, and global bureaucratic and humanitarian networks involved in the Guji-Gedeo response. These platforms were initially successful in bringing together different stakeholders for the purpose of coordination. However, when the experienced UN and federal coordinators were reallocated from Guji-Gedeo to different assignments in early autumn, we see the subnational bureaucrats' support for the EOC led response subside. They were frequently invited to attend meetings but stayed away. "We tried. We begged many times," a federal government bureaucrat explained.

In September 2018, government authorities again declared the crisis over. They stated that it was safe for people to return and that it was important that they do so. The coffee harvest was approaching, which was vital to the local economy. Furthermore, the areas they had fled to were already food insecure and too densely populated. In addition, the buildings that were being used to shelter IDPs were urgently needed for their original purposes, such as schooling children and housing supplies.

As it was unclear which government agency was responsible for organising returns, the subnational authorities took it upon themselves to organise coaches to transport people back to their places of origin. Some claim that they were following orders from the federal government; others indicated that the decision was made at the subnational level. The EOC got no advanced warning:

They are very secretive. Even though they organized the return, we were not aware. They organized by themselves....I mean they mobilize buses and trucks to send back the people to there, we have been informing them that please inform us in advance so that we can go there and see the process and support. But so far, we don't know. (UN staff, November 3, 2018)

Some IDPs claim that people were put under pressure to return. Many who were bussed back were unable to return to their home villages because they did not feel safe and/or because their houses and farms had been destroyed. As a result, some ended up living in displacement sites nearby their original homes, whereas others fled again. The consequence of pressuring people to return to areas that were not yet safe was that many soon fled their home villages again. They came to be called 'reverse returnees.' Figure 5 provides a chronological overview of the core events in 2018.

\subsection{Humanitarian Network Governance: Connections, Alignments and Trust}

This section analyses how the network structures and governance arrangements that marked the response inhibited the effective onboarding of subnational bureaucrats with the federal-global response. As already indicated, the Ethiopian state is not a monolith but is made up of a network of actors who do not necessarily see things the same way. The government actors involved in the Guji-Gedeo crisis were the federal government, the zonal government of Oromia, the zonal government of SNNP, and the district (woreda) governments of Guji and Gedeo, as well as all the municipality (kebele) level government actors (see Figure 6). The field EOCs in Guji and Gedeo were federal government initiatives led by the National Disaster Risk Management Commission (NDRMC). Although the federal government was powerful, the day-to-day lives of people were primarily shaped by subnational authorities.

Subnational authorities, on occasion, sought to resist federal control. "The challenge is that in this country even though the head of NDRMC or the deputy prime 


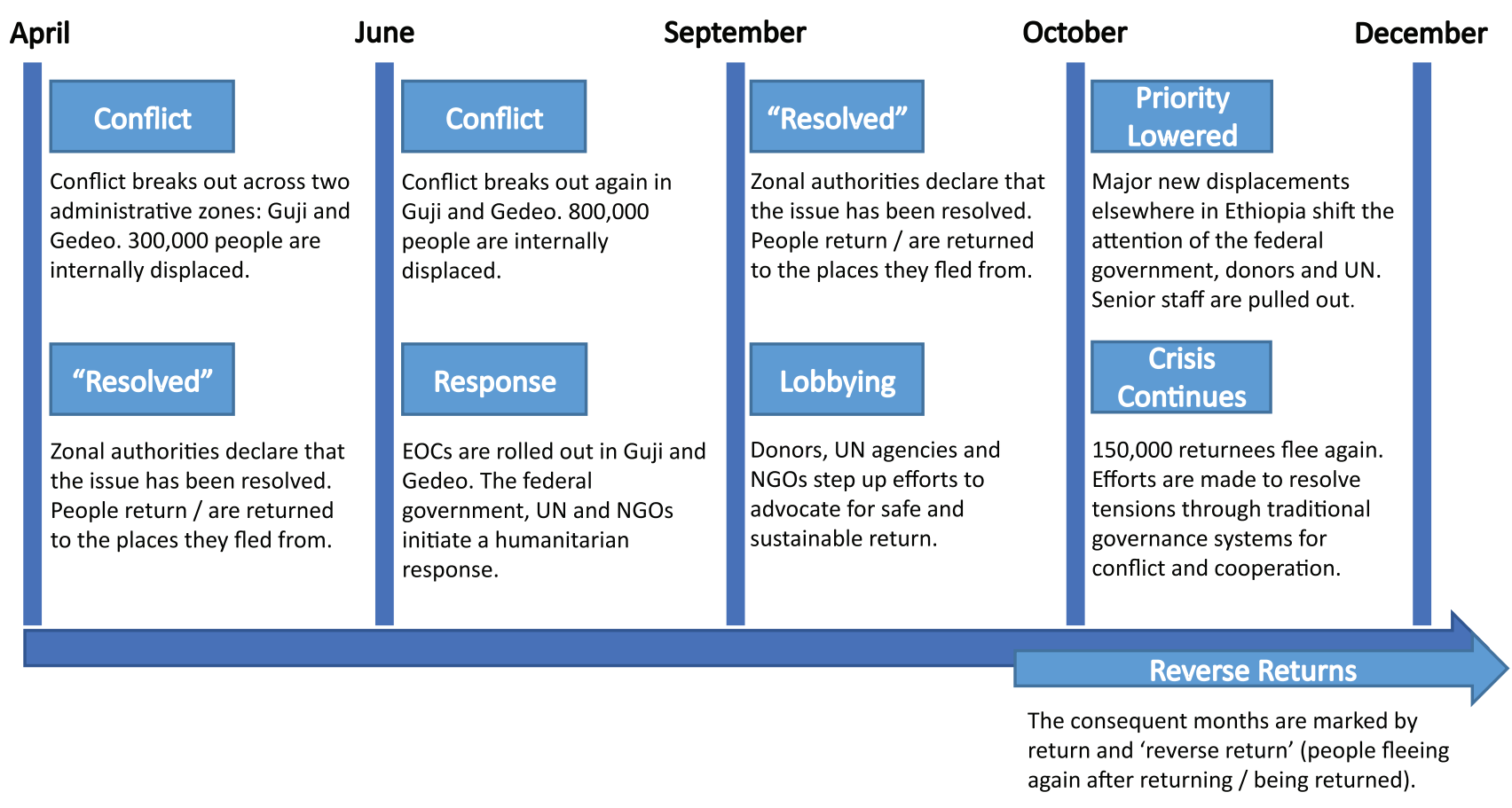

Figure 5. Timeline 2018 Guji-Gedeo displacement crisis. Source: Author.

minister said yes or something, it does not mean that zonal and woreda or regional authorities say yes. It's not automatic" (UN staff, November 3, 2018).

NDRMC's background and strength lay in disaster management in the context of natural hazards, not conflict-induced crises. In line with this background, the EOC's mandate was limited to emergency response. It did not include return and reconciliation or security. As such, subnational bureaucrats had a valid reason not to involve (or inform) the EOC of related activities:

It wasn't our NDRNC colleagues who said the people have to return. It wasn't NDRMC colleagues blocking access. This was zonal, woreda, regional. I mean there is no smoking gun. We don't know who was giving what directives, but uh, it wasn't that. (Donor staff, December 13, 2018)
The United Nations supported the EOCs in Guji Gedeo through the UNOCHA. The international dimensions of the humanitarian response in Guji and Gedeo added further layers of complexity. Most humanitarian agencies were global entities, with offices at the subnational, national, and global level. As is standard practice in the sector, they coordinated with other organisations working on the same issues (e.g., shelter, health, food, protection) at all levels through standing bodies (clusters) convened by lead agencies. The EOCs in Guji and Gedeo coordinated between the clusters at field level. Figure 7 depicts the humanitarian sector in simplified form: Vertical networks of organisations that are horizontally interlinked at different levels through the vertical cluster system. The government of Ethiopia led the clusters at national levels and below with UN agencies acting as co-leads.

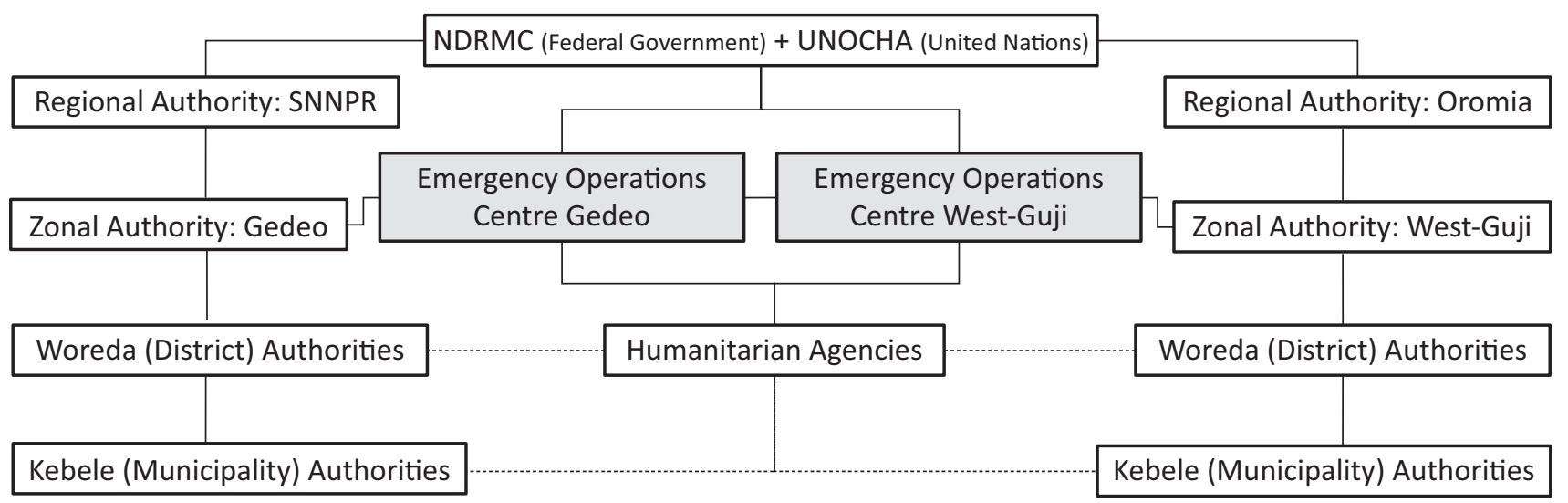

Figure 6. The institutional context of the EOCs in Guji and Gedeo (simplified). Source: Author. 


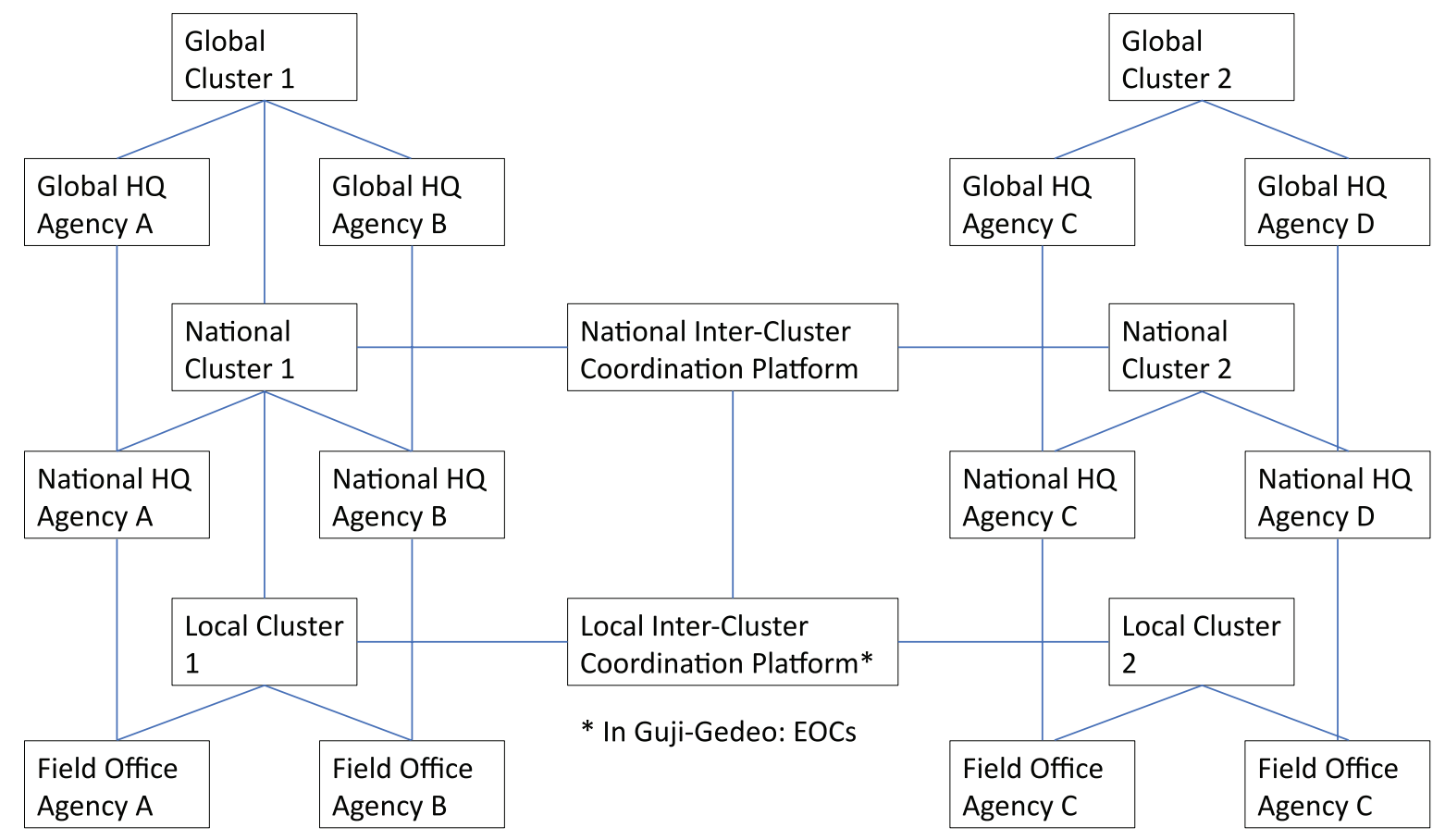

Figure 7. The humanitarian cluster system (simplified). Source: Author.

As such, NDRMC and UNOCHA were the NGBs leading the EOC. With one notable exception, the NGBs succeeded at getting humanitarian partners to align their efforts with the EOC. The main challenge they faced was keeping the subnational bureaucrats on board and engaged with the EOC-led response. Given the NGBs' lack of formal leverage over subnational bureaucrats, and the fact that return and security did not officially fall within the EOCs' remit, it was essential that the subnational bureaucrats saw the EOCs as valuable spaces for sharing their knowledge and furthering their interests. After all, they could also work around these structures (which they did).

However, it was much harder for the EOCs to establish legitimacy and trust with the subnational bureaucrats than with the humanitarians. This is in part because the NGBs responsible for managing the EOC were more closely aligned with the national-global ways of knowing than with the local ones. Most of the humanitarians stationed in Guji-Gedeo were only present in the area part-time, shuttling between Awasa or Addis Ababa and the affected region. All were on short-term assignments, lasting 1-3 months, as is common in the sector. Expat humanitarians tend to rotate quickly through assignments in different disaster settings around the globe. They often end up working with the same colleagues in different settings. Many national humanitarians rotate through short-term contracts with NGOs within their country. In times of disaster (such as in Guji-Gedeo), expats are flown in from abroad, and national staff are rapidly transferred from wherever they were stationed within their country to the affected area. This is called a 'surge.' A surge is necessary in times of disaster for the humanitarian community to get onto the ground and scale up within a reasonable timeframe. However, the result of this was that the vast majority of humanitarians, including Ethiopians, did not have local networks in Guji-Gedeo. As such, they drew primarily on national-global networks (such as the cluster system) for humanitarian information, validation, and resources. The NGBs leading the EOCs were centrally embedded in these national-global networks. However, they were significantly less well connected with the local networks in which the subnational bureaucrats were embedded. This idea is presented in Figure 8.

\section{Findings: Network Governance Arrangements and the Enclosure of the Knowledge Commons}

The article now presents the findings of the networkpower analysis outlined in Section 2. As described above, the networks that came together at the field EOCs were broadly divided into two clusters: the national-global cluster of the humanitarians and the local cluster of the subnational bureaucrats. Naturally, there were interconnections between these clusters, as well as great diversity within them. Nevertheless, when zooming out, it is the significant disconnect and misalignment between these two clusters that stands out. Given that the NGBs were centrally embedded in the national-global cluster, but not the local cluster, they held significant leverage over the humanitarians but not the subnational bureaucrats, as described below. This contributed to (the performance of) a broad consensus within the national-global cluster and the marginalisation of the local cluster at the EOC. As a consequence, the subnational bureaucrats were not effectively onboarded in the federal-global response and worked around it to achieve their goals. 


\section{Emergency Operations Centres}

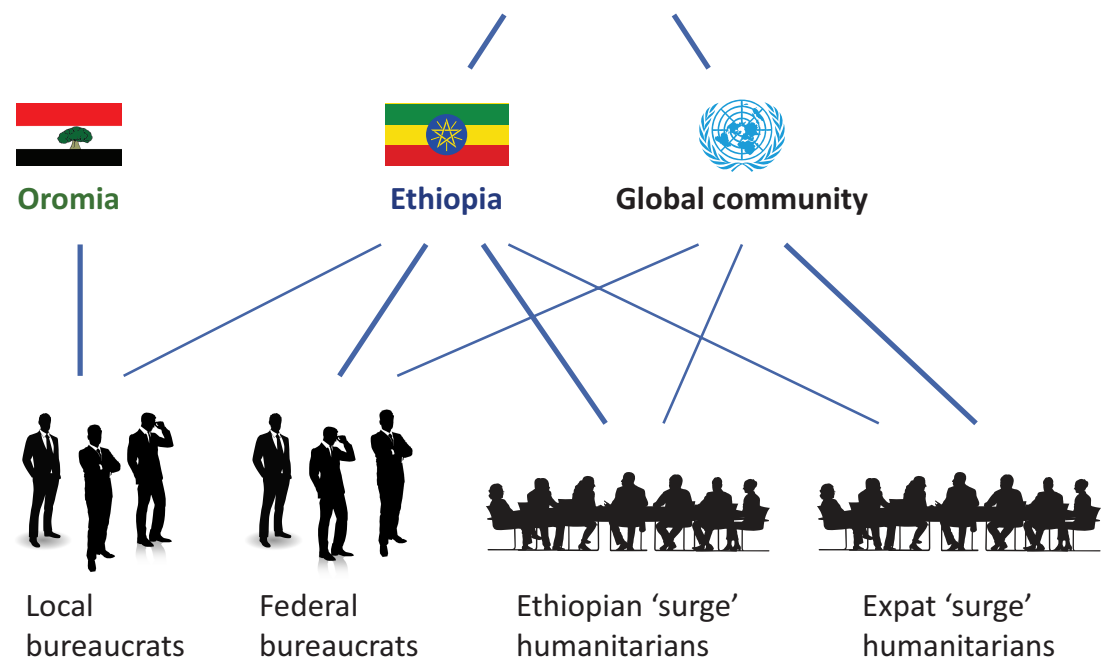

Figure 8. Embeddedness bureaucrats and humanitarians versus embeddedness EOCs in Guji-Gedeo. Source: Author.

This section describes the role power and knowledge governance played in this process.

\subsection{Power and Counter-Power: The Physical Enclosure of the Knowledge Commons}

The government's leverage over humanitarians (including UNOCHA) was ultimately underpinned by their visible power to block access to the field. Government actors could physically stop these agencies from directly acquiring knowledge of local circumstances in person. As described, in their efforts to counter globalnational control, some subnational bureaucrats initially tried to block humanitarian access to Guji-Gedeo, physically enclosing the knowledge commons. The federal government of Ethiopia, by contrast, could bar humanitarian agencies from operating in Ethiopia altogether. They could also block the virtual exchange of knowledge between field locations in Ethiopia and the wider world. The federal government owned the only telecommunications provider in Ethiopia and, as such, could physically disconnect humanitarians stationed in Guji-Gedeo from the wider national and global networks on which they depended.

In 2018, there were several deliberate communications black-outs ranging from several hours to several weeks. These black-outs were triggered to quell tensions and lower the risk of violence. Indeed, prior to his current role as prime minister, Dr. Abiy Ahmed founded the Ethiopian Information Network Security Agency (INSA) whose stated mission is to "secure cyber for peace, development and democracy."

Due to the current conflict situation, the internet was disconnected in all over eastern parts of the country. [Two weeks later] still internet connection is not working. I am using the government one which is connect- ed for emergency case. (INGO staff, emails, August 9 and 20, 2018)

\subsection{Power and Counter-Power: The Bureaucratic Enclosure of the Knowledge Commons}

UNOCHA's leverage over humanitarians and government actors was underpinned by its visible power to grant or deny access to connections and resources. This power sprang from its (network) position as lead UN humanitarian coordinator, donor liaison and emergency fund manager. Whilst globally a very influential player, in the context of the NDRMC led response, UNOCHA's official role was to support. The agency sought to strike a balance in its efforts to liaise between government and humanitarian partners at the field EOCs. However, the requirement to work through government structures made this challenging. "Some people regard OCHA like very close to the government" (UN staff, November 3, 2018).

NDRMC, as a federal agency, held significant leverage over the humanitarians, including UNOCHA. In addition to blocking access and triggering blackouts, the federal government also held the visible power to enclose the knowledge commons through bureaucratic means. They could block the publication of humanitarian information products or they could withhold their official approval for them, which made them hard to use. This strongly incentivised humanitarians to operate within the boundaries of knowledge management that were explicitly placed on them, for example, in the context of protecting Ethiopia's global image:

You know, in Ethiopia since 1984, there has not been a famine. Now the thing about famine is that it's a technical definition that you only know about it if you are collecting mortality data. We aren't allowed to collect mortality data. (UN staff, October 3, 2018) 
In field operations, humanitarian actors were expected to use only the data and information that had been put together, or at least signed off on, by government actors. They overwhelmingly complied with the bureaucratic restrictions that were placed on what knowledge they could publicly share or use. This public performance of compliance contributed to the global-national cluster appearing as one powerful, aligned block.

Subnational bureaucrats had the ability to bypass the EOC and work around this block. In addition to attempts to physically enclose the knowledge commons, described above, they also used bureaucratic means to influence (or subvert) the federal-global response, for example by withholding mission-critical information:

I think if the figures have not been endorsed by the zone, how do we respond? How do we target?....I'm sure there are various partners who work in those areas. They are ready actually to intervene but we need that official...we don't have any official information so we cannot tell the partners to help with need. (IOM staff, coordination meeting at EOC in Dilla, Gedeo, November 2, 2018)

Working around the EOC, some subnational bureaucrats sought to influence the movement of reverse returnees by not registering them. As such, they were absent from the official beneficiary lists humanitarians had to use to organise aid: "They know how many people arrived...but they are not officially registering people-those, as I said, reverse returns....The reason they explain always is that if they register that become kind of a pull factor for that they stay here" (UN staff, November 3, 2018).

\subsection{Against Participation: The Hierarchical Enclosure of the Knowledge Commons}

The power imbalances between the federal-global and local clusters at the EOC also determined whose norms, values and expectations influenced interactions at the EOCs. In Guji-Gedeo, the routines and established ways of working of the federal-global cluster dominated. As a result, the participation of key local stakeholders was (inadvertently) restricted.

The mandate of the EOC was formally limited to emergency response and did not include return, reconciliation, or security. Efforts in these areas were conducted at local level by subnational bureaucrats and traditional leaders. Given the challenge the issue of return posed to the EOC-led response, knowledge sharing and coordination with these actors would have greatly helped. However, nobody expected the traditional leaders-or representatives of the IDPs themselves-to attend EOC meetings or read EOC communications. All written and spoken communications at the EOC were in English, which is the lingua franca in the humanitarian world and often the default for knowledge sharing. By adopting this common practice, the EOCs inadvertently linked people's ability to participate meaningfully to their level of English. This also disadvantaged some subnational bureaucrats who, unlike their Ethiopian counterparts based at international NGOs and UN agencies, were not used to working in this language. Inviting actors to share their knowledge without actually enabling them to do so on an equal footing does little to foster multivocality or trust. It hierarchically limits access and participation in the commons by the extent to which stakeholders conform to the norm in terms of knowledge and skills-in this case, the national-global norm.

\subsection{Against Multivocality: The Moral Enclosure of the Knowledge Commons}

The visible and invisible power aligned with the federalglobal cluster, described above, also fed into NDRMC and UNOCHA's hidden power to frame narratives. These NGBs were able to call on shared (or imposed) understandings of what is right and what is important in their efforts to 'morally' enclose the public knowledge commons. As indicated above, many organisations actively engaged in self-censorship and upheld strict communication policies to ensure that their 'on the record' knowledge focused on what was 'right' and 'important.' 'Off the record knowledge' was generally withheld from the public commons: "We have to situate ourselves in a way that, first of all, we are not contradicting the government narrative because that can also get us into trouble" (UN staff, December 14, 2018).

Due to their network position (see Figure 7) UNOCHA and NDRMC held significant influence over decisions as to what constituted 'the right information.' Their field coordinators, who shuttled in between Addis Ababa and the EOCs in Guji-Gedeo, were able to prioritise, select, and frame information for audiences at different levels. This was also the case for staff taking care of minutes, field reports, website content, and so on:

Especially when you're dealing with complex issues, you're dealing with issues that-we don't have some kind of straight jacket kind of decisions. There are always various valid opinions from different people. But then our role in that is, first of all, to provide the narrative, the right narrative from the field. What is happening in the field. We provide information that will help people to reach to a consensus, you know. (UN staff, December 14, 2018)

In the humanitarian sector, what is right and important has been articulated in standards, principles, and guidelines (such as the UN principles of sustainable voluntary return). The humanitarians interviewed for this study all considered these institutions to be central to their mission and organisation's identity. Furthermore, they also held significant strategic value to these actors, lending legitimacy to humanitarian organisations that (are seen to) adhere to them. Many humanitarians strategically 
use the language and framings provided by these universal standards to communicate more effectively with leading agencies and donors (e.g., UNOCHA) to get legitimacy and funding. Given these strategic interests, the humanitarian organisations in Guji-Gedeo were both morally and materially aligned with this broad set of values. Humanitarian knowledge brokers in Guji-Gedeo could, therefore, count on their assent when framing narratives in accordance with these norms, values, and priorities.

In Guji-Gedeo, the issue of 'forced return' was of central importance to the humanitarian response. Knowledge brokers framed related information in terms of the UN principles of voluntary return in safety and dignity. In doing so, they drew both on their hidden power to frame narratives and the invisible power of shared values to further a sense of common purpose within the federal-global cluster. However, the subnational bureaucrats were embedded in different knowledge networks. They viewed the displacement crisis through the lens of the host communities and the pressure the IDP crisis placed on 'their people':

So, in that case in the guidelines I'm not sure whether the zonal people are fully aware of each and every single context. And I don't know whether they feel that they need to respect. Because again the federal people does not have any leverage to regional and zonal people. (UN staff, November 3, 2018)
Ideally, the EOCs would have facilitated a dialogue whereby all stakeholders explored how local and nationalglobal principles (such as the UN principles of voluntary return in safety and dignity) connected with their own interests and professional identities in the specific context of the response, and how this could be translated into a broad common purpose. Instead, the subnational bureaucrats were confronted with a top-down framing as to what was right or important, with little exploration as to how this connected to their perspectives and priorities.

\subsection{The Downwards Spiral Towards the Enclosure of the Knowledge Commons}

The EOC-led response in Guji-Gedeo started with two (largely) disconnected clusters that were each embedded in different knowledge networks. Given the interconnection between knowledge and trust, this disconnect gave each cluster the impression that the other was not just wrong (e.g., on the topic of return), but illintentioned. This mistrust was not effectively redressed. As a result, stakeholders did not act in a pro-commons manner by facilitating the free and open sharing of knowledge. Instead, over time, they actively or passively contributed to its ever greater enclosure, deepening the disconnect and misalignment between the two clusters and furthering a downwards spiral towards a breakdown of collaboration in Guji-Gedeo (see Figure 9).

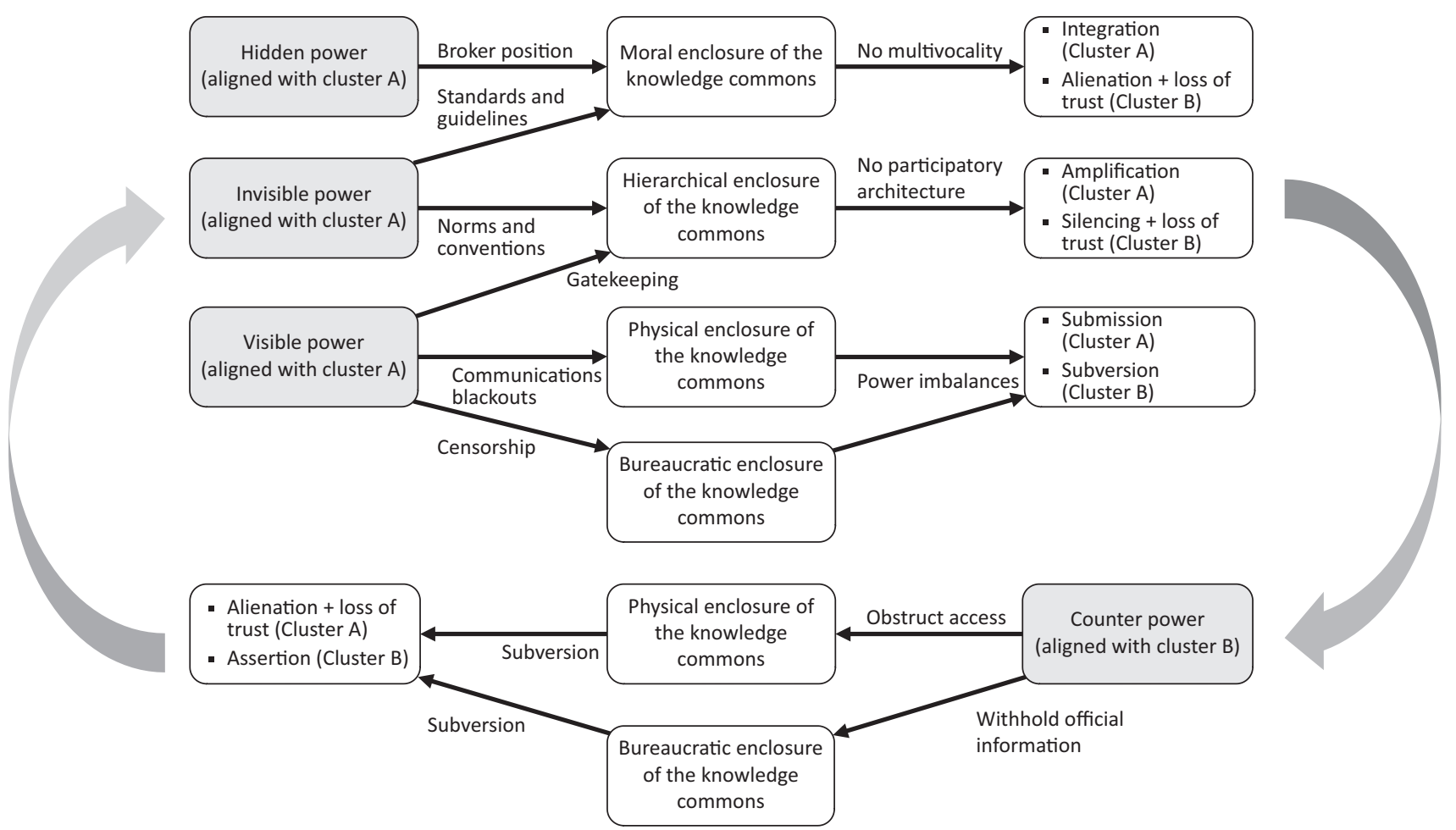

Figure 9. The downwards spiral towards a breakdown in collaboration at the EOCs in Guji-Gedeo. Notes: Cluster A refers to the federal government and humanitarians; cluster B refers to sub-national bureaucrats. Source: Author. 


\section{Conclusion and Discussion}

This article has approached humanitarian knowledge as a complex commons and a wicked problem: a networked resource that connects a wide range of actors and is subject to social dilemmas. It contributes to the wicked commons literature by exploring these social dilemmas through the lens of network power. Focusing on knowledge-trust, it analyses how connections, affiliations, and network positions interlink with different forms of power to shape stakeholders' incentives to sacrifice direct benefits (e.g., control over information) for a collective good (e.g., shared learning). The article contends that disconnected and misaligned ways of knowing are among the core challenges that mark a wicked commons. The article suggests a robust action approach to knowledge governance as a solution in principle to this challenge. Robust action allows for the interlinking of different ways of knowing towards the development of a (very) broad sense of common purpose, shared identity and trust. It facilitates decentralised trial and error learning, as well as the (partial) integration of local context specific knowledge with a national-global evidentiary knowledge base. This has the potential to improve both daily operations as well as understanding of the core problems that mark the wicked commons. Robust action does not require consensus and is fundamentally incompatible with the moral, hierarchical, physical and bureaucratic enclosure of the knowledge commons. Looking at governance arrangements, this article has analysed how network power shaped the enclosure of the knowledge commons, rendering a robust action approach non-viable.

This article now concludes with a tentative response to the question how do network governance arrangements shape incentives towards enclosure of the knowledge commons?

The EOC led response in Guji-Gedeo was marked by hierarchical networks that were broadly divided into two clusters: the national-global and the local. The NGBs in charge of the response were centrally embedded in the former and only loosely connected to the latter. As such, they held significant leverage over the expat and national humanitarians and little over the subnational bureaucrats. This meant that the EOCs did not (could not) operate as multivocal, participatory spaces (see Figure 9). Power aligned with the national-global cluster fostered the hierarchical enclosure of the knowledge commons, which amplified the ways of knowing of that cluster and silenced those of the local cluster. It also contributed to the moral enclosure of the knowledge commons, fostering (the performance of) a broad sense of consensus within the global-national cluster, which alienated the local cluster. As a result, there was a clustering of trust and belief in the internal legitimacy of the governance arrangements. Most humanitarians were effectively onboarded in the federal-global response, but not the subnational bureaucrats. Given that the latter were able to work around the EOC, they instead exerted influence over the response through physical and bureaucratic control over the knowledge commons. Efforts on both sides to enclose the knowledge commons fed into a downwards spiral towards depleted trust and a breakdown in collaboration.

To create an environment that is conducive to a robust action approach, local coordination/communication platform conveners (such as field EOCs) need to be positioned so as to enable their coordinators to act as facilitative leaders who can redress power imbalances, foster participation and multivocality. This means that they cannot be NGBs who are in a position of significant influence over some network members, or have a strong prior alignment with some network clusters, and not others. It also means that they cannot be strongly affiliated with such NGBs. Given the importance of local engagement, local learning and local leadership in the face of wicked problems, national-global support for local problems might be best governed through independent subnational NGBs whose leadership equally represents the different global, national and local knowledge-clusters that comprise the commons at the subnational level.

\section{Acknowledgments}

This project was sponsored by the Netherlands Organization for Scientific Research (NWO), Division of Social Sciences, Smart Disaster Governance (Project 409-14-003), under the supervision of principal investigator Dr. ir. Kees Boersma.

\section{Conflict of Interests}

The author declares no conflict of interests.

\section{References}

Aldrich, D. P. (2012). Building resilience: Social capital in post-disaster recovery. Chicago, IL: University of Chicago Press.

Ansell, C., \& Gash, A. (2008). Collaborative governance in theory and practice. Journal of Public Administration Research and Theory, 18(4), 543-571.

Barnett, M. N. (2011). Empire of humanity: A history of humanitarianism. Ithaca, NY: Cornell University Press.

Bekele, D. (2019). The role and utilization of indigenous communication in conflict resolution: The case of Gedeo people South Ethiopia (Unpublished Doctoral dissertation). Addis Ababa University, Addis Ababa, Ethiopia. Retrieved from http://etd.aau. edu.et/bitstream/handle/123456789/18844/ Desalegn\%20Bekele.pdf

Boersma, K., Ferguson, J., Groenewegen, P., \& Wolbers, J. (2014). Beyond the myth of control: Toward network switching in disaster management. In S. R. Hiltz, M. S. Pfaff, L. Plotnick, \& P. C. Shih (Eds.), Proceed- 
ings of the 11th International ISCRAM Conference (pp. 123-127). Philadelphia, PA: Pennsylvania University.

Castells, M. (2007). Communication, power and counterpower in the network society. International Journal of Communication, 1(1), 29.

Daviter, F. (2019). Policy analysis in the face of complexity: What kind of knowledge to tackle wicked problems? Public Policy and Administration, 34(1), 62-83.

Debelo, A. R. (2012). Dynamics of political ethnicity and ethnic policy in Ethiopia: National discourse and lived reality in the Guji-Gedeo case. The Journal of Oromo Studies, 19(1), 1-36.

Debelo, A. R., \& Jirata, T. J. (2018). "Peace is not a free gift": Indigenous conceptions of peace among the Guji-Oromo in Southern Ethiopia. Northeast African Studies, 18(1/2), 201-230.

Desportes, I., Mandefro, H., \& Hilhorst, D. (2019). The humanitarian theatre: Drought response during Ethiopia's low-intensity conflict of 2016. The Journal of Modern African Studies, 57(1), 31-59.

Food and Agriculture Organization of the United Nations. (n.d.). Complex emergency. Food and Agriculture Organization of the United Nations. Retrieved from www.fao.org/emergencies/emergency-types/ complex-emergencies

Feldman, M. S., Khademian, A. M., Ingram, H., \& Schneider, A. S. (2006). Ways of knowing and inclusive management practices. Public Administration Review, 66, 89-99.

Ferraro, F., Etzion, D., \& Gehman, J. (2015). Tackling grand challenges pragmatically: Robust action revisited. Organization Studies, 36(3), 363-390.

Fleming, P., \& Spicer, A. (2014). Power in management and organization science. The Academy of Management Annals, 8(1), 237-298.

Gaventa, J. (2005). Reflections of the uses of the 'power cube' approach for analysing the spaces, places and dynamics of civil society participation and engagement (CFP evaluation series 2003-2006, No. 4). The Hague: MFP Breed Netwerk.

Gioia, D. A., Corley, K. G., \& Hamilton, A. L. (2013). Seeking qualitative rigor in inductive research: Notes on the Gioia methodology. Organizational Research Methods, 16(1), 15-31.

Hendriks, T. D., \& Boersma, F. K. (2019). Bringing the state back in to humanitarian crises response: Disas- ter governance and challenging collaborations in the 2015 Malawi flood response. International Journal of Disaster Risk Reduction, 40, 1-7.

Henry, A. D., \& Dietz, T. (2011). Information, networks, and the complexity of trust in commons governance. International Journal of the Commons, 5(2), 188-212.

Hess, C., \& Ostrom, E. (Eds.). (2007). Understanding knowledge as a commons: From theory to practice. Cambridge, MA: MIT Press.

Hilhorst, D., Desportes, I., \& de Milliano, C. W. (2019). Humanitarian governance and resilience building: Ethiopia in comparative perspective. Disasters, 43, S109-S131.

Jack, S. L. (2008). Approaches to studying networks: Implications and outcomes. Journal of Business Venturing, 25(1), 120-137.

Kefale, A. (2013). Federalism and ethnic conflict in Ethiopia: A comparative regional study. New York, NY: Routledge.

Melis, S., \& Hilhorst, D. (in press). When the mountain broke: disaster governance in Sierra Leone. Disaster Prevention and Management.

Ostrom, E. (2010). A long polycentric journey. Annual Review of Political Science, 13(1), 1-23.

Ostrom, E., Gardner, R., \& Walker, J. (1994). Rules, games, and common-pool resources. Ann Arbor, MI: University of Michigan Press.

Pratt, M. G. (2009). From the editors: For the lack of a boilerplate-Tips on writing up (and reviewing) qualitative research. Academy of Management Journal, 52(5), 856-862.

Provan, K. G., \& Kenis, P. (2008). Modes of network governance: Structure, management, and effectiveness. Journal of Public Administration Research and Theory, 18(2), 229-252.

Weber, E. P., \& Khademian, A. M. (2008). Wicked problems, knowledge challenges, and collaborative capacity builders in network settings. Public Administration Review, 68(2), 334-349.

Yarnell, M. (2018). The crisis below the headlines: Conflict displacement in Ethiopia. Washington, DC: Refugees International. Retrieved from www. refugeesinternational.org/reports/2018/11/14/thecrisis-below-the-headlines-conflict-displacement-inethiopia

\section{About the Author}

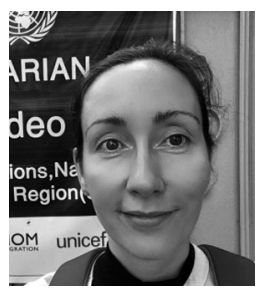

Femke Mulder is a Researcher in the field of disaster and humanitarian studies. She has a background in organisation sciences and anthropology. Her area of expertise is disaster knowledge management towards societal resilience with a focus on localisation, participation, ICT4D and data justice. Femke has over 15 years of professional experience in the NGO and local government sectors. 